\title{
Perfil demográfico de idosos não institucionalizados e sua percepção sobre alimentos funcionais
}

\section{Demographic profile of non-institutionalized elderly and their perception of functional food \\ Perfil demográfico de los ancianos no institucionalizados y su percepción sobre los alimentos funcionales}

\author{
Ana Lúcia Félix de Pontes ${ }^{I}$; Luípa Michele SilvaII; Cássia Surama Oliveira da Silva ${ }^{I I I}$; Luiza Sonia Rios Ascuitti ${ }^{\text {IV }}$; \\ Antonia Oliveira Silva ${ }^{\mathrm{V}}$, Maria da Conceição Rodrigues Gonçalves ${ }^{\mathrm{VI}}$
}

\begin{abstract}
RESUMO: O objetivo do estudo foi analisar o perfil demográfico de idosos e sua percepção sobre alimentos funcionais. A pesquisa foi descritiva, com delineamento transversal, e abordagem quantitativa, envolvendo 200 idosos, em João Pessoa - PB, em 2011. Na análise, utilizou-se o software SPSS, versão 19, teste de quiquadrado com nível de significância de p<0,05. São resultados: maioria do sexo feminino, faixa etária entre 60 e 69 anos, com um salário mínimo; e maioria viúvos. Quanto aos hábitos alimentares, 90,5\% consumiam diariamente frutas e hortaliças, 35,5\% referiram não comer frituras e gorduras; $45 \%$ bebiam mais de cinco xícaras de líquido e 51,5\% atestaram estado de saúde regular. Como conclusão, tem-se que a maioria dos idosos tem um bom conhecimento sobre os alimentos funcionais e os utiliza frequentemente. A percepção dos idosos sobre os alimentos funcionais e seus hábitos alimentares foi de extrema importância para o planejamento de futuras ações, indispensáveis para a promoção da saúde dessa população.

Palavras-Chave: Saúde; idoso; envelhecimento; alimento funcional.
\end{abstract}

ABSTRACT: The study analyzed demographic profile and perceptions of functional foods among 200 elderly in João Pessoa, Paraíba, Brazil, in 2011. The design was cross-sectional and the approach, quantitative. The analysis used SPSS software, version 19, chi-square test with a $p<0.05$ significance level. The results were: mostly female, from 60 and 69 to old, earning one minimum wage; and mostly widowers. Eating habits featured $90.5 \%$ consumed fruits and vegetables daily; $35,5 \%$ reported not eating fried foods and fats; $45 \%$ drank more than five cups of liquid; and $51.5 \%$ self-rated their state of health as fair. In conclusion most of the elderly had good knowledge of functional foods and used them often. Their perceptions of functional foods and their eating habits were extremely important to planning future actions, which are essential to health promotion for this population. Keywords: Health; elderly; aging; functional food.

RESUMEN: El objetivo del estudio fue analizar el perfil demográfico de los ancianos y su percepción de los alimentos funcionales. La investigación fue descriptiva con diseño transversal y un abordaje cuantitativo, involucrando a 200 ancianos, en João Pessoa -Paraíba, Brasil, en 2011. En el análisis, se ha utilizado el software SPSS, versión 19, prueba de chi cuadrado con un nivel de significación de $\mathrm{p}<0,05$. Los resultados son: en su mayoría mujeres, con edades comprendidas entre 60 y 69 años, recibiendo un salario mínimo; y en su mayoría viudas. En cuanto a las costumbres alimentarias, el 90,5\% consumía frutas y verduras; el $35,5 \%$ informó que no comía alimentos fritos y grasas; un $45 \%$ bebía más de cinco tazas de líquido y el $51,5 \%$ afirmó que tenía estado de salud regular. En conclusión, la mayoría de los ancianos tiene un buen conocimiento de los alimentos funcionales y los ingieren con frecuencia. La percepción de los ancianos sobre los alimentos funcionales y sus hábitos de alimentación fue sumamente importante para la planificación de acciones futuras, esenciales para la promoción de la salud de esta población. Palabras Clave: Salud; anciano; envejecimiento; alimento funcional.

\section{INTRODUÇÃO}

A longevidade humana tem sido uma questão instigante na primeira década do século XXI. Vários fatores complexos interagem no processo de con- ceituar envelhecimento. Pode ser definido como um estado fisiológico, em que há um declínio progressivo das funções dos órgãos, acompanhado de doenças

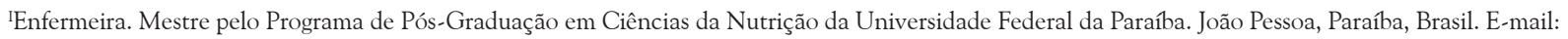
ana.lucia.felix@hotmail.com.

IIEnfermeira. Doutoranda do Programa de Pós-Graduação em Enfermagem da Universidade Federal da Paraíba. João Pessoa, Paraíba, Brasil. E-mail: luipams@gmail.com.

IIIEnfermeira. Mestre pelo Programa de Pós-Graduação em Ciências da Nutrição da Universidade Federal da Paraíba. João Pessoa, Paraíba, Brasil. E-mail: suramajpa@hotmail.com.

IVNutricionista. Professora da Faculdade Ciências Médicas da Paraíba. João Pessoa, Paraíba, Brasil. E-mail: luiza.asciutti@terra.com.br.

vEnfermeira. Doutora em Enfermagem. Professora do Programa de Pós-Graduação em Enfermagem da Universidade Federal da Paraíba. João Pessoa, Paraíba, Brasil. E-mail: alfaleda@hotmail.com.

VINutricionista. Doutora em Farmácia. Professora do Programa de Pós-Graduação em Ciências da Nutrição da Universidade Federal da Paraíba. João Pessoa, Paraíba, Brasil. E-mail: raulceica@ig.com.br.

VIIRecorte da dissertação de mestrado de Ana Lúcia Félix de Pontes, intitulada Características sociodemográficas, econômicas, hábitos alimentares e percepção sobre alimentos funcionais de idosos não institucionalizados, defendida em 2012, Universidade Federal da Paraíba-UFPB. 
relacionadas à idade ${ }^{1}$, atingindo um número cada vez maior de indivíduos em todo o mundo.

Em menos de 40 anos, o número de idosos no Brasil passou de 3 milhões, em 1960, para 7 milhões, em 1975, e 20 milhões em 2008 - um aumento de quase $700 \%$, em menos de 50 anos. Hoje, a cada ano, são incorporados 650 mil novos idosos à população brasileira, sendo que a maior parte dela está sendo acometida de doenças crônicas e algumas limitações funcionais ${ }^{2}$.

Com o processo de envelhecimento, os idosos começam a apresentar condições peculiares que condicionam o seu estado nutricional. Fatores envolvidos nas causas das deficiências nutricionais, verificadas na população idosa, em parte, são condicionados por processos inerentes às alterações fisiológicas desse processo. Outros são influenciados, sobretudo, pelas enfermidades e por fatores relacionados à situação socioeconômica em que se encontra o idoso. Portanto, não podem ser considerados em sua totalidade, como parte do processo natural do envelhecimento ${ }^{3}$.

Diante desse fato e do envelhecimento mundial da população, a comunidade científica depara-se com maior necessidade de aprofundar a compreensão sobre hábitos alimentares saudáveis na promoção e manutenção da independência e autonomia do idoso ${ }^{4}$.

Frente ao exposto, e considerando a escassez de estudos sobre o uso de alimentos funcionais por população idosa, esta pesquisa ${ }^{\mathrm{VII}}$ teve como objetivo analisar o perfil demográfico de idosos não institucionalizados e a sua percepção sobre alimentos funcionais.

\section{REVISÃo DE LITERATURA}

O conceito de alimentos funcionais tem sua origem nos diversos hábitos alimentares, milenares e saudáveis do Japão e da China. As antigas culturas chinesa, indiana, egípcia e grega trabalhavam muito com o conceito de comida-remédio, ou de alimentos terapêuticos, atribuindo propriedades preventivas e/ ou curativas a quase todos os alimentos, bem como reconhecendo as condições adequadas de seu preparo e consumo. Hipócrates e Galeno já utilizavam amplamente alimentos na prescrição diária para a cura de diversos males 5 .

A alimentação adequada tem como componentes as frutas e vegetais, que contêm fitoquímicos, polifenois, flavonoides e vitaminas essenciais ao organismo humano. A ingestão desses alimentos é uma das estratégias, aplicadas para aumentar a esperança de vida e retardar ou reverter os danos associados ao processo normal de envelhecimento, sendo evidenciado que uma dieta rica em frutas e vegetais reduz efetivamente alguns tipos de câncer e doenças cardiovasculares ${ }^{6}$. Um estudo demonstrou que o resveratrol, tirosol e o hidroxitirosol não só ativam os genes da longevidade, como promovem a sobrevivência da célula? ${ }^{7}$ E isso tem auxiliado a realização de estudos que busquem incentivar o uso de alimentos ricos nessas substâncias e outras no combate a doenças crônicas e agravos à saúde.

O papel desse tipo de alimentação, baseada no consumo frequente de frutas, hortaliças, cereais integrais, grãos e laticínios desnatados, é otimizar a nutrição, com o objetivo de maximizar as funções fisiológicas do idoso e garantir o aumento da saúde e do bem-estar, trazendo como resultado a redução no risco de desenvolver doenças decorrentes da má alimentação, como as deficiências nutricionais, bem como as doenças crônicas não transmissíveis $(\mathrm{DCNT})^{8}$.

Devido aos altos índices de DCNT, hoje há uma intervenção dietoterápica baseada na redução da ingestão de alimentos ricos em açúcares, gorduras, sódio e restrição ao uso do álcool. Com isso, estratégias têm sido montadas para aumentar o consumo de frutas, verduras e legumes, sendo uma delas o programa 5 ao dia, iniciado nos Estados Unidos e atualmente implantado em mais de 40 países $^{9,10}$.

\section{Metodologia}

Trata-se de uma pesquisa do tipo descritiva, com delineamento transversal e abordagem quantitativa, com a participação de 200 idosos, com idade entre 60 e 90 anos de ambos os sexos. Ressalta-se que 100 idosos são acompanhados pelo Ambulatório de Geriatria do Hospital Universitário Lauro Wanderley (HU), da Universidade Federal da Paraíba (UFPB), e outros 100 idosos são participantes de Grupos de Convivência do Programa de Atenção Básica à Pessoa Idosa (PAPI), localizados na região sul do município de João PessoaPB. A pesquisa foi realizada no período de maio a agosto de 2011, utilizando-se como instrumento o Mini Nutritional Assessment (MNA) ${ }^{11}$.

A amostra foi do tipo probabilística, na qual todos os elementos do conjunto possuem a mesma chance de serem entrevistados. Para se obter dados representativos dos grupos da zona sul e adjacências, foram escolhidos, aleatoriamente, quatro grupos, sendo três da zona sul e um grupo do bairro adjacente (Castelo Branco II), além do mesmo número de idosos atendidos no Ambulatório de Geriatria do HU-UFPB que aceitaram participar da pesquisa.

Os critérios de inclusão foram: idade igual ou superior a 60 anos; idosos que frequentassem o PAPI; idosos com consultas agendadas no Ambulatório de Geriatria do HU-UFPB, que demonstrassem interesse pelo tema e apresentassem condições cognitivas de participar do estudo. O entrevistado, após leitura do Termo de Consentimento Livre e Esclarecido, do conhecimento sobre a pesquisa e do esclarecimento de dúvidas, registrava sua a assinatura nesse documento. 
O desenvolvimento do estudo seguiu os preceitos éticos disciplinados pela Resolução no 196/96 do Conselho Nacional de Saúde ${ }^{12}$, aprovado pelo Comitê de Ética do HU-UFPB, sob o número 725/10 e número da CAAE 0560.0.126.000-10 520/2010.

A coleta de dados ocorreu mediante entrevista individual. Os dados foram analisados no programa Statistical Package for Social Sciences SPSS ${ }^{\circledR}$ para Windows ${ }^{\circledR}$ versão 19.0 , submetidos a tratamento estatístico por meio de análise bivariada e teste de associação do quiquadrado $\left(\boldsymbol{X}^{2}\right)$.

\section{Resultados e Discussão}

Entre os idosos, a maioria era do sexo feminino, da faixa etária entre 60 e 69 anos, com média de idade de 68,34 $\pm 6,73$ anos e com renda familiar média de um salário mínimo. Houve predominância de viúvas; a maioria possui apenas o primeiro grau completo.
A doença de maior ocorrência foi o distúrbio oftalmológico, conforme mostra a Tabela 1.

A maioria informou que seu estado de saúde era regular, entretanto houve uma significativa diferença entre os grupos, $43 \%$ dos idosos dos grupos de convivência contra 60\% dos idosos do HULW, segundo a Tabela 1.

Os idosos participantes dos grupos de convivência apresentaram uma associação estatisticamente significativa entre a faixa etária e os distúrbios oftalmológicos $(p=0,021)$, e nos atendidos no HULW a correlação ocorreu entre o estado de saúde referido e a faixa etária $(\mathrm{p}=0,035)$.

Quanto aos hábitos alimentares desses idosos, 91,5\% faziam três refeições diariamente; $90,5 \%$ consumiam diariamente frutas e hortaliças; $35,5 \%$ referiram consumir frituras e gorduras uma vez por semana; $45 \%$ bebiam mais de cinco xícaras de líquido e a maioria $(51,5 \%)$ informou ter um estado de saúde regular, sendo

TABELA 1: Distribuição das variáveis sociodemográficas, econômicas e de saúde de idosos dos Grupos de Convivência e do HULW. João Pessoa - PB, Brasil, 2011.

\begin{tabular}{|c|c|c|c|c|c|c|}
\hline \multirow[b]{2}{*}{ Variáveis } & \multicolumn{2}{|c|}{ Grupos de Convivência } & \multicolumn{2}{|c|}{ HULW } & \multicolumn{2}{|c|}{ Total } \\
\hline & $f$ & $\%$ & $f$ & $\%$ & $f$ & $\%$ \\
\hline \multicolumn{7}{|l|}{ Sexo } \\
\hline Feminino & 97 & 97 & 99 & 99 & 196 & 98 \\
\hline Masculino & 3 & 3 & 1 & 1 & 4 & 2 \\
\hline \multicolumn{7}{|l|}{ Faixa etária } \\
\hline 60 a 69 anos & 53 & 53 & 62 & 62 & 115 & 57,5 \\
\hline 70 a 79 anos & 39 & 39 & 30 & 30 & 69 & 34,5 \\
\hline 80 anos e mais & 8 & 8 & 8 & 8 & 16 & 8 \\
\hline \multicolumn{7}{|l|}{ Estado civil } \\
\hline Solteiro & 15 & 15 & 21 & 21 & 36 & 18 \\
\hline Casado & 24 & 24 & 47 & 47 & 71 & 35,5 \\
\hline Divorciado & 11 & 11 & 7 & 7 & 18 & 9 \\
\hline Viúvo & 50 & 50 & 25 & 25 & 75 & 37,5 \\
\hline \multicolumn{7}{|l|}{ Escolaridade } \\
\hline Sem escolaridade & 4 & 4 & 8 & 8 & 12 & 6 \\
\hline $1^{\mathrm{o}} \mathrm{grau}$ & 63 & 63 & 68 & 68 & 131 & 65,5 \\
\hline $2^{\circ}$ grau & 28 & 28 & 16 & 16 & 44 & 22 \\
\hline $3^{\circ}$ grau & 5 & 5 & 8 & 8 & 13 & 6,5 \\
\hline \multicolumn{7}{|l|}{ Fontes de Recursos financeiros } \\
\hline Aposentadoria & 59 & 59 & 62 & 62 & 121 & 60,5 \\
\hline Pensão & 25 & 25 & 12 & 12 & 37 & 18,5 \\
\hline Trabalho & 3 & 3 & 7 & 7 & 10 & 5 \\
\hline Sem rendimento & 13 & 13 & 19 & 19 & 32 & 16 \\
\hline \multicolumn{7}{|l|}{ Estado de saúde } \\
\hline Excelente & 14 & 14 & 4 & 4 & 18 & 9 \\
\hline Bom & 42 & 42 & 34 & 34 & 76 & 38 \\
\hline Regular & 43 & 43 & 60 & 60 & 103 & 51,5 \\
\hline Ruim & 1 & 1 & 2 & 2 & 3 & 1,5 \\
\hline \multicolumn{7}{|c|}{ Doenças crônicas não transmissíveis(*) } \\
\hline Hipertensão Arterial & 55 & 35,3 & 68 & 37,1 & 123 & 36,2 \\
\hline Problemas Oftalmológicos & 58 & 37,2 & 73 & 39,9 & 131 & 38,6 \\
\hline Complicações Cardíacas & 6 & 3,8 & 10 & 5,5 & 16 & 4,7 \\
\hline Amputações & 1 & 0,6 & 2 & 1,1 & 3 & 0,8 \\
\hline Dislipidemia & 36 & 23,1 & 30 & 16,4 & 66 & 19,7 \\
\hline
\end{tabular}

(*) Podia ser registrado mais de 1 tipo de doença crônica. 
pertinente enfatizar que eles apresentavam autonomia para se alimentar, conforme a Tabela 2 .

Pode-se destacar que o consumo de frituras e gorduras esteve mais presente entre os idosos do HULW do que entre os participantes de grupos de convivência. É importante ressaltar que apenas no ambiente hospitalar 3\% dos idosos relataram se alimentar com dificuldade.

Quanto aos alimentos funcionais, 66\% deles afirmaram conhecê-los e $90 \%$ do total de idosos os consumiam. Ao se visualizar independentemente os grupos, os do HULW, majoritariamente (76\%), referiram ter conhecimento desses insumos; já os dos grupos de convivência relataram um consumo maior (92\%), de acordo com a Tabela 3.

\section{Perfil social e econômico dos sujeitos}

Os resultados trazem o predomínio do sexo feminino na população estudada, o que está em consonância com a tendência da feminização do envelhecimento, que se mantém com o avançar da idade ${ }^{13-15}$. Essas idosas, em sua maioria, estão entre a faixa etária de 60 a 69 anos, fenômeno que pode ser explicado pelo crescimento gradual dessa população. A proporção de idosos em 1991 representava 1,3\% da população, havendo um incremento, no ano de 2002, para $1,7 \%$. Dentre essa população, o índice de analfabetismo vem decrescendo, já que, em 1991, 44\% dos idosos não sabiam ler e, em 2002, este índice foi reduzido para 33,3\%. Em 2010, no município onde foi realizado o presente estudo, o índice foi de 7,9\% ${ }^{13}$.

A viuvez acaba se tornando uma característica comum entre essas mulheres, sendo importante frisar que a perda do companheiro e as mudanças produzidas na viuvez são acontecimentos considerados trágicos ou naturais na vida e que geram profundas transformações ${ }^{16}$.

Fato importante observado neste estudo é o grau reduzido de analfabetismo registrado ${ }^{4,17}$, o que mostra a evolução da população idosa, graças aos investimentos na educação, fazendo com que eles procurem

TABELA 2: Distribuição dos hábitos alimentares dos idosos dos Grupos de Convivência e do HULW. João Pessoa - PB, Brasil, 2011

\begin{tabular}{ccccccc}
\hline Variáveis & \multicolumn{2}{c}{ Grupos de Convivência } & \multicolumn{2}{c}{ HULW } & \multicolumn{2}{c}{ Total } \\
\cline { 2 - 7 } & $\mathrm{f}$ & $\%$ & $\mathrm{f}$ & $\%$ & $\mathrm{f}$ & $\%$ \\
\hline Refeições ao dia & & & & & & \\
Três & 9 & 9 & 8 & 8 & 17 & 8,5 \\
Frituras e Gorduras & 91 & 92 & 92 & 183 & 91,5 \\
1x por semana & 32 & 32 & 12 & 12 & 44 & 22 \\
3x por semana & 29 & 29 & 40 & 40 & 69 & 34,5 \\
4 a 6x por semana & 25 & 25 & 35 & 35 & 60 & 30 \\
Não come & 14 & 14 & 13 & 13 & 27 & 13,5 \\
Frutas e Hortaliças & & & & & & \\
Diariamente & 91 & 91 & 90 & 90 & 181 & 90,5 \\
3x por semana & 9 & 9 & 7 & 7 & 16 & 8 \\
4 a 6x por semana & 0 & 0 & 3 & 3 & 3 & 1,5 \\
Quantidade de líquidos & & & & & & \\
Menos de 3 xícaras & 9 & 9 & 15 & 15 & 24 & 12 \\
3 a 5 xícaras & 43 & 43 & 43 & 43 & 86 & 43 \\
Mais de 5 xícaras & 48 & 48 & 42 & 42 & 90 & 45 \\
Com dificuldade & - & - & 3 & 3 & 3 & 1,5 \\
\hline Sem dificuldade & 100 & 100 & 97 & 97 & 197 & 98,5 \\
\hline Modo de alimentac̃ã & & & & &
\end{tabular}

TABELA 3: Distribuição do conhecimento sobre alimentos funcionais e sua utilização entre os idosos dos Grupos de Convivência e do HULW. João Pessoa - PB, Brasil, 2011.

\begin{tabular}{lccccccc}
\hline \multirow{2}{*}{ Variáveis } & & \multicolumn{2}{c}{$\begin{array}{c}\text { Grupos de } \\
\text { Convivência }\end{array}$} & \multicolumn{2}{c}{ HULW } & \multicolumn{2}{c}{ Total } \\
\cline { 3 - 8 } & & $\mathrm{f}$ & $\%$ & $\mathrm{f}$ & $\%$ & $\mathrm{f}$ & $\%$ \\
\hline \multicolumn{2}{l}{ Conhecimento sobre alimentos funcionais } & & & & & & \\
& Sim & 56 & 56 & 76 & 76 & 132 & 66 \\
Uso de alimentos funcionais & Não & 44 & 44 & 24 & 24 & 68 & 34 \\
& & & & & & & \\
& Sim & 92 & 92 & 88 & 88 & 180 & 90 \\
& Não & 8 & 8 & 12 & 12 & 20 & 10 \\
\hline
\end{tabular}


cada vez mais aumentar o seu conhecimento. Sendo assim, a redução do analfabetismo é decorrência do melhoramento das condições de vida da pessoa idosa, através dos centros de convivência, programas de alfabetização para adultos e outros.

Quanto à procedência de recursos financeiros, verifica-se que as aspirações pessoais e a perspectiva de vida da pessoa idosa são atingidas por intermédio da atividade profissional. Portanto, a formação do indivíduo e o trabalho são questões importantes a serem levantadas quando da discussão da aposentadoria. Para muitos idosos, a aposentadoria é causadora de um empobrecimento gradativo, porque não só inviabiliza gastos com lazer, como também não favorece uma predisposição psicológica para a prática de atividades prazerosas; por esse motivo, é constante a preocupação maior com o atendimento das necessidades básicas ${ }^{13,15}$.

Nesse contexto, a maioria da população idosa deste estudo era composta por aposentados e pensionistas, com ganho mensal de um salário mínimo, o que poderia influenciar, negativamente, na sua qualidade de vida e até na aquisição de uma alimentação mais saudável. É sempre uma variável importante a ser destacada, pois estudos apresentam uma taxa maior de idosos alfabetizados no Sul e no Sudeste do Brasil do que no Nordeste ${ }^{17,18}$.

No presente estudo, o estado de saúde foi considerado regular na autoavaliação da maioria, o que difere de pesquisas comparativas entre outros grupos, como em Portugal ${ }^{19}$, embora esta diferença não tenha alcançado significância estatística entre um e outro. Mas, no estudo em questão, houve uma estatística significativa quando cruzada a faixa etária e o estado de saúde regular. Em outras pesquisas brasileiras, os achados mostram que são poucos os idosos que percebem de forma negativa o seu estado de saúde ${ }^{20-22}$.

Entre as condições de saúde autorreferidas, os distúrbios oftalmológicos apresentaram uma frequência elevada, principalmente entre os idosos participantes dos grupos de convivência, e há uma forte correlação com a idade. A ocorrência de Hipertensão Arterial Sistêmica (HAS) e de Dislipidemia também foi bastante elevada, ressaltando-se o fato de não ser a idade avançada o único fator para a sua explicação ${ }^{6,15,23}$.

A HAS é um problema grave de saúde pública, no Brasil e no mundo, considerada como um dos mais importantes fatores de risco para o desenvolvimento de doenças cardiovasculares, cerebrovasculares e renais, sendo responsável por, pelo menos, $40 \%$ das mortes por acidente vascular encefálico, 25\% das mortes por doença arterial coronariana e, em combinação com o diabetes, $50 \%$ dos casos de insuficiência renal terminal ${ }^{14}$.

\section{Hábitos alimentares dos idosos}

É notória a contribuição dos grupos de convivência, assim como as consultas em hospital ambulatório específico para idosos, tendo em vista que realizam palestras e fornecem orientações, fazendo com que essa população tenha mais cuidado com a sua alimentação e a sua saúde, o que auxilia em uma melhor qualidade de vida.

A dislipidemia também é considerada um dos fatores de risco mais importantes para o desenvolvimento da doença arterial coronariana em indivíduos idosos com até 80 anos de idade, embora esse risco diminua com a idade ${ }^{4}$. Dados do estudo Framingham apontam que a prevalência de hipercolesterolemia (colesterol total $\geq 240 \mathrm{mg} / \mathrm{dL}$ ) em pessoas idosas do sexo feminino é mais frequente na faixa dos 65 a 74 anos, declinando gradativamente após essa idade ${ }^{24}$.

Nesse caso, a alimentação exerce também um papel importante na sua origem, assim como de outras alterações na saúde dessa faixa da população. Assim, a orientação nutricional é especialmente importante para os idosos por causa das mudanças fisiológicas relacionadas ao envelhecimento ${ }^{14}$. Como exemplo, tem-se que as refeições devem ser pouco abundantes e distribuídas, de forma que não sobrecarreguem demasiadamente o estômago do idoso; devem ser preparadas para facilitar a mastigação e permitir fácil digestão; aconselha-se evitar a utilização de condimentos fortes e alimentos excessivamente gordurosos e / ou servidos muito quentes ${ }^{9}$. Deve-se estimular, mesmo aqueles idosos com dificuldade para se alimentar, o consumo de uma alimentação saudável e que possa suprir as suas necessidades nutricionais ${ }^{3,8}$.

Nas entrevistas, foi perguntado com que frequência ingeriam comidas gordurosas ou frituras; em sua maioria, eles afirmaram que faziam tal ingestão uma vez por semana ou não comiam gordura, confirmando outros estudos $^{4,6,23}$ que recomendam a ingestão controlada de gordura, tanto em portadores de HAS quanto em pessoas saudáveis, particularmente para evitar o aumento de complicações como doenças coronárias e obesidade ${ }^{9,10}$.

Esta análise concorda com os resultados de um estudo em São Paulo, no qual foi pesquisado, separadamente, o consumo diário de frutas, legumes e verduras de adultos paulistanos. Verificou-se que $43 \%$ dos adultos consumiam frutas diariamente, $46,8 \%$ verduras e somente $18,1 \%$ ingeriam legumes ${ }^{25}$.

Nesse mesmo enfoque, um estudo constatou que $50 \%$ dos adultos franceses, de ambos os sexos, consumiam diariamente cinco ou mais porções de frutas, legumes e verduras $^{26}$. Merece destacar que a alimentação tem significação cultural, comportamental e afetiva, de maneira singular, que jamais pode ser desprezada. Ressalta-se que uma população com maior nível de instrução e mais acesso à informação tem, cotidianamente, uma prática de consumo de alimentos saudáveis e menos abuso de drogas como álcool. Com isso, frutas, verduras, cereais e carnes magras constam de seus pratos; gorduras, frituras e açúcares aparecem menos em suas declarações acerca de dieta alimentar cotidiana.

Estudos epidemiológicos sugerem que pessoas com dietas ricas em frutas e vegetais têm um menor 
risco de várias doenças crônicas e mortalidade precoce do que as pessoas com dietas pobres nesses alimentos. Muitas vezes, esse efeito é atribuído aos micronutrientes antioxidantes encontrados nos alimentos vegetais. Os nutrientes antioxidantes, em especial os carotenoides na forma de $\beta$-caroteno, têm recebido especial atenção com referência à nutrição do idoso $0^{27,28}$.

Nesse sentido, os fatores associados aos hábitos alimentares têm sido alvo de vários estudos, pois são considerados fatores de risco para uma série de doenças crônico-degenerativas. Sob esta perspectiva, estudos mostram que independente do sexo, o total calórico da dieta diminui com a idade, chegando a ser insuficiente no grupo etário acima de 60 anos ${ }^{8,9,14}$.

Por tudo isso, a nutrição geriátrica tem uma importância especial, visto que, nessa fase, existem diferentes implicações nutricionais que variam desde desnutrição proteica calórica, alterações metabólicas e interações medicamentosas, até deficiências de micronutrientes, que, associadas a fatores sociais, econômicos e psicológicos, podem contribuir para o declínio e comprometimento de várias funções orgânicas vitais ${ }^{28}$. Durante o acompanhamento geriátrico, é importante uma avaliação nutricional completa e criteriosa, pois a partir dela é possível identificar os idosos em risco nutricional aumentado para danos à saúde e estabelecer programas de intervenção, os quais devem contribuir para que essa população receba um suporte nutricional mais adequado às suas necessidades e orientações sobre alimentação saudável ${ }^{29}$.

\section{Utilização de alimentos funcionais}

Quanto aos alimentos funcionais e sua utilização entre os idosos entrevistados, a maioria tinha conhecimento deles e os ingeria com frequência, sendo os mais citados: mamão, banana, laranja, maçã e aveia, consumidos, de acordo com eles, para o equilíbrio dos intestinos e ossos, para evitar câncer e anemia, para ajudar a queimar o colesterol, entre outras funções. $\mathrm{O}$ aumento na ingestão de frutas, legumes e verduras pela população em geral tem sido uma prioridade das políticas públicas de saúde em muitos países ${ }^{30}$.

Esses alimentos apresentam benefícios à saúde por sua atividade antioxidante, a qual é promovida por componentes como flavonoides, vitamina $\mathrm{E}$, carotenoides, e outros que têm a capacidade de neutralizar radicais livres, os quais também são responsáveis pelo envelhecimento acelerado ou por doenças degenerativas ${ }^{1}$.

Nesse contexto, os alimentos funcionais reforçam o efeito salutar de substâncias cuja ingestão por meio da dieta habitual é insatisfatória. Novas tendências alimentares justificam o desenvolvimento de alimentos funcionais, devido a hábitos adquiridos pelas pessoas que tendem a se alimentar de maneira pouco balanceada e pobre em nutrientes essenciais ao organismo ${ }^{31}$.

Para o estímulo de uma alimentação saudável, é preciso mostrar sua importância, bem como fazer com que se torne uma rotina na vida do idoso ${ }^{8}$. Em um estudo, idosos afirmaram consumir diariamente frutas, hortaliças e bebiam mais de cinco copos de água por dia, fato muito importante, pois dietas ricas em legumes, verduras e frutas têm sido associadas à redução de doenças cardiovasculares e alguns tipos de câncer ${ }^{9}$.

A ingestão de alimentos funcionais deve ser acompanhada de uma alimentação fracionada, pois esta contribui para o controle da saciedade e, consequentemente, a prevenção de uma sobrecarga metabólica, a qual pode ser mais prejudicial a idosos com problemas digestivos ou dificuldades em alimentar-se. Os idosos necessitam de uma maior atenção dos profissionais de saúde quanto à adequação do fracionamento das refeições, para que não ocorra supressão de alguma alimentação diária e, em todas elas, estejam presentes alimentos saudáveis ${ }^{32,33}$. Dessa maneira, não apenas estarão mantendo o peso corporal, mas auxiliando na prevenção de agravos à saúde.

Os benefícios dos alimentos funcionais são focados em diversas áreas, incluindo a prevenção e o tratamento de doenças cardiovasculares, diversos tipos de câncer, diabetes e inflamações e aumento da resposta imune, bem como retardo no processo de envelhecimento e extensão de uma vida saudável e, nesse sentido, uma grande variedade de substâncias bioativas de origem vegetal ou animal tem sido investigada, por seu potencial de propriedades funcionais e fisiológicas.

\section{Conclusão}

Os resultados assinalam que o perfil sociodemográfico dos idosos está caracterizado por baixa escolaridade, viuvez e condição socioeconômica de renda mínima; a condição de saúde aponta a HAS e problemas oftalmológicos como as principais DCNT identificadas. E quanto à percepção sobre os alimentos funcionais, mostrou-se satisfatória, pois além de afirmarem conhecê-los e usá-los, os idosos têm sido acompanhados por equipes que buscam melhorar ainda mais essa compreensão e estimulam uma alimentação saudável, no intuito de diminuir agravos à saúde.

É importante ressaltar que os idosos declararam que o uso de alimentos funcionais melhorou o estado nutricional, favorecendo a aquisição de bons hábitos alimentares, como o consumo de mais frutas e hortaliças e a restrição à ingestão de gorduras e frituras, mostrando satisfação quanto aos resultados. Além de um adequado conhecimento sobre alimentos funcionais e a sua utilização na promoção da saúde, supõe-se que estes hábitos foram desenvolvidos pelos idosos em virtude das informações recebidas nos grupos de convivência e nos atendimentos especializados em geriatria.

Uma alimentação saudável e a manutenção do estado nutricional adequado são fatores fundamentais para um envelhecimento saudável; por isso, conhecer 
a percepção dos idosos sobre alimentos funcionais e seus hábitos alimentares foi de extrema importância, pois viabiliza o planejamento de futuras ações, indispensáveis para a promoção da saúde dessa população.

Podem ser apontadas como limitações do estudo a escassez de pesquisas similares para enriquecer as comparações e a reduzida amostra e dois cenários que impedem a generalização dos achados.

\section{REFERÊNCIAS}

1.Romano AD, Serviddio G, de Matthaeis A, Bellanti F, Vendemiale G. Oxidative stress and aging. Department of Medical and Occupational Sciences, University of Foggia, Italy. J Nephrol. 2010; 23(15):29-36.

2.Veras R. Envelhecimento populacional contemporâneo: demandas, desafios e inovações. Rev Saude Publica. 2009; 43:548-54.

3.Campos MAG, Pedroso ERP, Lamounier JA, Colosimo EA, Abrantes MM. Estado nutricional e antropometria em idosos: revisão da literatura. Rev Med Minas Gerais. 2007;17(3/4):169-70.

4.Fiedler MM, Peres GP. Fuctional status and associated factors among the elderly in a southern Brasilian city: a population-based study. Cad Saúde Pública. 2008; 24:409-15. 5.Oliveira MN, Sivieri K, Alegro JHA, Saad SMI. Aspectos tecnológicos de alimentos funcionais contendo probióticos. Rev Bras Cienc Farm. 2002; 38(1): 1-21.

6.Mukherjee S, Lekli I, Gurusamy N, Bertelli AAA, Das DK. Expression of the longevity proteins by both red and white wines and their cardioprotective components, resveratrol, tyrosol, and hydroxytyrosol. Radic Biol Med. 2009; 46:573-8.

7.Sousa KT, Mesquita LAS, Pereira LA, Azeredo CM. Baixo peso e dependência funcional em idosos institucionalizados de Uberlândia (MG), Brasil. Ciênc saúde coletiva. 2014; 19: 3513-20 .

8.Carvalho MM, Lino LLA. Avaliação dos fatores que caracterizam a berinjela (Solanum melongena L.) como um alimento funcional. Nutrire. 2014; 39(1): 130-43.

9. Teixeira PDS, Reis BZ, Vieira DAS, Costa D, Costa JO, Raposo OFF, et al. Intervenção nutricional educativa como ferramenta eficaz para mudança de hábitos alimentares e peso corporal entre praticantes de atividade física. Ciênc saúde coletiva. 2013; 18: 347-56.

10.Gomes FS, Cruz R, Castro IRR. Promoción de frutas y hortalizas en Brasil: la contribución del programa 5 al día. Rev Chil Nutr. 2006; 33(1):295-99.

11.Soini H, Routasalo P, Lagström H. Characteristics of the Mini-Nutritional Assessment in elderly home-care patients. Eur J Clin Nutr. 2004; 58(1):64-70.

12.Ministério da Saúde (Br). Conselho Nacional de Saúde. Comissão Nacional de Ética em Pesquisa. Resolução no 196 de 10 de outubro de 1996: diretrizes e normas regulamentadoras de pesquisa envolvendo seres humanos. Brasília (DF): CNS; 1996.

13.Instituto Brasileiro de Geografia e Estatística. Primeiros resultados definitivos do Censo 2010. Brasília (DF): IBGE; 2011.
14.Luna RC, Nascimento CC, Asciutti LS, Franceschini $\mathrm{SD}$, Filizola RG, Diniz AD, et al. Relation between glucose levels, high-sensitivity C-reactive protein, body mass index and serum and dietary retinol in elderly in population-based study. Arch of Gerontol and Geriatr. 2012; 54: 462-8.

15.Gonçalves LTH, Leite MT, Hildebrandt LM, Bisogno SC, Biasuz S, Falcade BL. Convívio e cuidado familiar na quarta idade: qualidade de vida de idosos e seus cuidadores. Rev bras geriatr gerontol. 2013; 16: 315-25. 16.Carreira L,Botelho MR,Matos PCB, Torres MM, Salci MA. Prevalência de depressão em idosos institucionalizados. Rev enferm UERJ. 2011; 19: 268-73.

17.Clares JWB, de Freitas MC, Galiza FT, Almeida PC. Necessidades relacionadas ao sono/repouso de idosos: estudo fundamentado em Henderson. Acta Paul Enferm. 2012; 25: 54-9.

18.Pereira GN, Morsch P, Lopes DGC, Trevisan MD, Ribeiro A, Navarro JHN, et al. Fatores socioambientais associados à ocorrência de quedas em idosos. Ciênc saúde coletiva. 2013; 18: 3507-14.

19.Araújo J, Ramos E, Lopes Carla. Estilos de vida e percepção do estado de saúde em idosos Portugueses de zonas rural e urbana. Acta Med Port. 2011; 24: 79-88.

20.Benedetti TB, Petroski EL, Gonçalves LT. Condições de saúde nos idosos de Florianópolis. Arq Catarin Med. 2006; 35(1):44-51.

21.Hartmann ACVC. Fatores associados a autopercepção de saúde em idosos de Porto Alegre [tese de doutorado]. Porto Alegre (RS): Universidade Católica do Rio Grande do Sul; 2008.

22.Carvalho FF, Santos JN, Souza LM, Souza NRM. Análise da percepção do estado de saúde dos idosos da região metropolitana de Belo Horizonte. Rev bras geriatr gerontol. 2012; 15: 285-94.

23. Caetano JA, Costa AC, Santos ZMSA, Soares E. Descrição dos fatores de risco para alterações cardiovasculares em um grupo de idosos. Texto contexto - enferm. 2008; 17:327-35.

24.Moriguchi EH, Michelon E, Vieira JLC. Dislipidemia em idosos. In: Freitas E, Py L, editoras. Tratado de Geriatria e Gerontologia. Rio de Janeiro: Guanabara Koogan; 2002. p:239-48.

25. Figueiredo ICR, Jaime PC, Monteiro CA. Factors associated with fruit and vegetable intake among adults of the city of São Paulo, Southeastern Brazil. Rev Saude Publica. 2008; 42:777-85.

26.Eustáquio C, Druesne-Pecollo N, Latino-Martel P, Dauchet L, Hercberg S, Bertrais S. Socioeconomic diferences in fruit and vegetable consumption among middle-aged French adults: adherence to the 5 a day recommendation. J Am Diet Assoc. 2008; 108:2021-30. 27.Agudo A, Cabrera L, Amiano P, Ardanaz E, Barricarte A, Berenguer T, et al. Fruit and vegetable intakes, dietary antioxidant nutrients, and total mortality in Spanish adults: findings from the Spanish cohort of the European Prospective Investigation into Cancer and Nutrition. Am J Clin Nutr, 2007; 85:1634-42.

28.Kuczmarski MF, Weddle DO. American Dietetic Association University of Delaware, Newark, DE, USA. J Am Diet Assoc. 2005; 105:616-33. 
29.Azevedo MR, Horta BL, Gigante DP, Victora CG, Barros FC. Fatores associados ao sedentarismo no lazer de adultos na coorte de nascimentos de 1982, Pelotas, RS. Rev Saude Publica. 2008;42(2):70-7.

30.Palanca V, Rodriguez E, Señoráns J, Reglero G. Bases cientificas para el desarollo de com actividad biológica combinada. Alimentos funcionales. Nutr Hosp(Madrid). 2006; 21:199-202.

31.Neutzling MB, Rombaldi AJ, Azevedo MR, Hallal PC. Factors associates with fruit and vegetable intake among adults in a southern Brasilian city. Cad Saúde Pública. 2009; 25:2365-74.

32. Lorga Adalberto, Paola Angelo de, Scatolini Neto Argemiro, Halperin Cidio, Moreira Dalmo, Hachul Denise et al . I Diretrizes do Grupo de Estudos em Cardiogeriatria da Sociedade Brasileira de Cardiologia. Arq Bras Cardiol. 2002; 79(Suppl 1): 1-46.

33. Barbieri AFS, Chagas IA, Santos MA, Teixeira CRS, Zanetti ML. Consumo alimentar de pessoas com diabetes mellitus tipo 2. Rev enferm UERJ. 2012; 20: 155-60. 